\title{
The Survival Status and Predictors of Mortality Among Stroke Patients at North West Ethiopia
}

\author{
Nigusie Walelgn' \\ Gebre Yitayih Abyu' \\ Yeshaneh Seyoum' \\ Samuel Derbie Habtegiorgis $\mathbb{D}^{2}$ \\ Molla Yigzaw Birhanu (D) ${ }^{2}$ \\ 'Department of Adult Health Nursing, \\ College of Medicine and Health Sciences, \\ Bahirdar University, Bahirdar, Ethiopia; \\ ${ }^{2}$ Department of Public Health, College of \\ Health Sciences, Debre Markos \\ University, Debre Markos, Ethiopia
}

Correspondence: Molla Yigzaw Birhanu; Samuel Derbie Habtegiorgis Email mollayigzaw33@gmail.com; kasadr21@gmail.com
Introduction: Stroke is one of the commonest non-communicable disease types that has a great public health impact both in developed and developing countries. However, in Ethiopia, the long-term survival status of stroke patients is not very understood. This study aimed at assessing survival status and predictors of mortality among stroke patients at Felege Hiwot comprehensive specialized hospital from September 1, 2014, to August 31, 2019, Bahirdar, North West Ethiopia.

Methods: An institutional-based retrospective cohort study was conducted using 368 registered stroke patients between September 1, 2014, and August 31, 2019. We used Kaplan-Meier together with a Log-rank test to compare the survival rate of the study participants using categorical variables and to compare covariate and both bi-variable and multivariable Cox proportional hazards regression analysis model was conducted to identify predictors of mortality among stroke patients. The association between outcome and independent variables was expressed using an adjusted hazard ratio (AHR) with a 95\% confidence interval and statistical significances were declared at P-value of $<0.05$.

Results: Fifty-six (15.2\%) of the 368 stroke patients included in the study died, and 312 $(84.8 \%)$ were correctly censored. The overall survival rate was $72.2 \%$ at 51 months of follow-up with a median survival time of 0.26 months. Age greater than 65 (AHR 6.31, 95\% CI 1.75-22.74), body temperature $>7.1$ degree centigrade $(\mathrm{AHR}=7.14,95 \%$ CI: $2.76-18.5)$, potassium level below $<2 \mathrm{mmol} / \mathrm{l}(\mathrm{AHR}=2,95 \% \mathrm{CI}: 1.9-23.53)$ and creatinine level $>1.2 \mathrm{mg} / \mathrm{dl}$ (AHR $=7.85,95 \% \mathrm{CI}: 2.7-22.6)$ were predictive predictors of mortality.

Conclusions: In the follow-up of 51 months, significant mortality occurred. Important predictive predictors of survival status were identified. Interventions should be focused on health education and awareness creation of the community for the early management of stroke.

Keywords: stroke, survival status, predictors, mortality, Ethiopia

\section{Background}

The World Health Organization defined stroke as rapidly developing clinical signs of focal (or global) disturbance of cerebral functions, lasting more than 24 hours or leading to death, with no apparent cause other than that of vascular origin. ${ }^{1}$ yeAngol Tikat," or Brain Attack, is a new term in Amharic for stroke. ${ }^{2}$ A stroke can be classified as either an ischemic or a hemorrhagic stroke. The blood supply to the brain is generally interrupted or reduced. ${ }^{1,3,4}$ Stroke is a multi-factorial disease where many determinants have been described. These determinants which lead to stroke are hypertension, diabetes, heart failure, human immune virus (HIV) ${ }^{5-11}$ and elevated red blood cells $(\mathrm{RBC}){ }^{12}$ Facial palsy cognitive impairment, 
hemiplegia, loss of consciousness and loss of vision are key signs and symptoms of stroke. ${ }^{13,14}$

Stroke is the second leading cause of mortality after ischemic heart disease and disability worldwide. In the 2017 Global Burden of Disease Report, worldwide, 5.5 million deaths and 132 million are left permanently disabled related to stroke. ${ }^{15-17}$ In the same year in Asia $(41.2 \%),{ }^{18}$ in Europe (19\%), ${ }^{19}$ and in Australia (14.9\%) of the stroke admission died. ${ }^{20}$ In Africa, the burden of stroke is high and ranges from $29 \%$ to $84 \%$ of stroke-related deaths and $14.3 \%$ of the disabled. ${ }^{16,21,22}$

Stroke prevalence was higher among young people (65 years) in high-income countries $(21.8 \%)$ than in lowincome countries $(15.7 \%){ }^{15}$ Its incidence has increased in East Asia and sub-Saharan Africa. ${ }^{17,23}$ Africa appears to be the global capital for strokes, with at least 6 Africans having a stroke every minute. The prevalence of strokes in Africa ranges from 15 per 100,000 in Ethiopia, to 963 per 100,000 in Egypt and 1460 per 100,000 in the Niger Delta region. $^{24}$

In Ethiopia, the burden of stroke is increasing and has become the reason for $7.5 \%$ to $19.3 \%$ of hospital admission, $5,8,14,20,39$ and approximately (11\% to $42.8 \%)$ death between (2014-2019). 5,8,11,13,20,27,33,40-45

Among the consequences of stroke were, among others, sudden death and depression $(12.4 \%$ to $42.9 \%) .{ }^{13,25}$ The wide range of medical complications of stroke are $16.5 \%$ to $27.6 \%$ of brain edema, ${ }^{26,27} 22.9 \%$ speech alteration, $3.5 \%$ bedsores, deep venous thrombosis (DVT) $4.1 \%$ because of immobility from stroke, ${ }^{13}$ increased intracranial pressure $(16.5 \%$ 26.1\%) infection 5.9-21.1\% and Seizure. ${ }^{13,27,28}$

In low- and middle-income countries (LMICs), including Ethiopia, there are several barriers to managing stroke patients, including limited stroke units, limited availability of resources, a shortage of adequately trained manpower, stroke prevention and treatment, a shortage of essential drugs, diagnostic facilities, and a lack of treatment guidelines. $^{21,24,29,30}$ Accurate information about the longterm prognosis after a stroke is important for the patient and balances the potential risks and benefits of treatment options, develops a treatment and discharge plan, and make rationing decisions if resources are limited. The information generated from this study will give baseline information for other researchers as well as there is limited recorded data on survival status and predictors of mortality among stroke patients at Felege Hiwot Comprehensive
Specialized Hospital, Bahir Dar, North West Ethiopia. That is why this study was conducted.

\section{Methods and Materials Study Setting, Period and Design}

The research was carried out at the Felege Hiwot Comprehensive Specialized Hospital in Bahir Dar, Northwest Ethiopia.Bahirdar is located 565 kilometers away from Addis Ababa, the capital city of Ethiopia. Felege Hiwot Hospital is a Comprehensive Specialized Hospital in Amhara Regional State and found in Bahir Dar town, capital city of the Amhara Regional State. Aside from currently serving patients, the hospital also serves as a teaching hospital for Bahir Dar University and various private Health Science Colleges. The city has one Comprehensive Specialist, one Specialized Hospital, one Primary Public Hospital and four private hospitals. This retrospective cohort study was conducted from September 1, 2014 to August 31, 2019, at the Felege Hiwot Comprehensive Specialized Hospital.

\section{Population}

All medical records of stroke patients in FHCSH admitted to the medical department were the source population and all medical records of stroke patients confirmed with imaging by CT/MRI from September 1, 2014 to August 31, 2019, were the study population.

\section{Eligibility Criteria}

This study included all stroke patients over the age of 15 , as well as stroke patient charts with CT scan/MRI confirmations. Patients with an unknown discharge status between September 1, 2014 and August 31, 2019, as well as incomplete and missing stroke patient chart records during the data collection period, were excluded.

\section{Sample Size Determination and Sampling Procedures}

\section{Sample Size Determination}

Sample size calculations for the survival status and predictors of mortality among stroke patients at FHCSH, for objectives one and two, were determined and the largest one was taken as the sample size for this research. That is, the sample size for the first objective was calculated using the following data and assumptions: $95 \%$ confidence interval, 80\% power, and hazard ratio (4.93) (Fekadu et al, 2019) the formula having two stepsâ

$$
M=\frac{\left(z^{a} / 2+z \beta\right)^{2}}{\theta^{2} \Pi(1-\Pi)}=\frac{(1.96+0.84)^{2}}{(\log (4.93))^{2} 0.5 \times 0.5}=66
$$


Where

- $\mathrm{M}$ is number of expected events (death)

$-z^{a} / 2$ is the significance level two sides (5\% the value is 1.96 )

$-z \beta$ have the value of $80 \%$ power $(0.84)$

- $\theta$ is logarithm of the hazard ratio (4.93) (Fekadu et al, 2019).

- $\Pi$ is the fraction of subjects allocated to the first group (by general cohort study expected ratio of 1 to 1 exposed-non exposed ratio)

step2, $\mathrm{n}=\frac{\mathrm{M}}{\mathrm{p}(\mathrm{event})}$

where $\mathrm{n}$ is the number of subjects to be followed,

$\mathrm{M}$-is the number of events (66) and $\mathrm{P}$ is the overall probability of an event (death) at the end of the study (21.6\%) (Fekadu et al, 2019) [31].

$$
n=\frac{M}{p(\text { event })}=\frac{66}{0.216}=306
$$

The sample size calculation for objective two is obtained from different literature and is calculated by Stata version 13 by considering the following assumptions: confidence level $95 \%$, power $80 \%$ and exposed to unexposed ratio of 1:1 by general cohort study, standard deviation and correlation of covariates 0.5 and 0 , respectively. Finally, by adding $20 \%$ of the lost follow-up, the final sample size was 368. Therefore, the sample size for this research was 368 , which is the largest among the sample sizes calculated for both the first and the second objectives.

\section{Sampling Procedure}

In Felege Hiwot Comprehensive Specialized Hospital, there is a list of stroke patients in the electronic database. Those over the age of fifteen were chosen first from those under the age of fifteen based on their electronic registrations. Five-year registered stroke patients confirmed by imaging using CT/MRI were included in this study. Then, study participants were selected by a simple random sampling technique with a lottery method.

\section{Data Abstraction Tool and Method}

Data were abstracted from patients' medical records using a data abstraction check list which was adapted from the WHO STEP wise approach to stroke surveillance 13,28,32 and from different literature results. ${ }^{33-35}$ Data were abstracted from records of stroke patients' registries from September 1, 2014 to August 31, 2019, G.C. confirmed using an imaging CT/MRI. Data was identified from patients' medical charts, including vital signs, lab results (blood glucose level, electrolyte level, creatinine, complete blood count), comorbidity, type of stroke, clinical presentation, GCS at baseline, length of hospital stay was calculated as the time gap from the patient's admission to hospital until discharged or died in the hospital, nursing care provided, time to have CT-scan, and all the comorbidities and medical complications were defined according to the AHA/ASA stroke management protocol. ${ }^{36}$ Death ascertainment was based on physician duty note along with suspected immediate causes of death from patient chart. Before the actual data abstraction, three BSc nurses (2 data collectors and 1 supervisor) who had experience of working in the medical ward were recruited and trained in the data abstraction procedure.

\section{Data Quality Assurance}

Prior to data abstraction, the adapted data extraction tool was evaluated by experienced researchers. Patients were enrolled from 2014 to 2019 two weeks before data abstraction, and their charts were cross-checked by taking $19(5 \%)$ and reviewing stroke patient charts with the check list to ensure the presence of the recorded variables in the patient's chart. As a result, some unrecorded variables were reduced by the data extraction tool. The principal investigator trained data abstractors and supervisors for one day. The training focused on introducing the data abstraction tools, the duration (initial and end) of the data abstraction period, how to access records and approach each item in the patients' records, wise use of time and data handling. During the data abstraction time, close supervision and monitoring was done by supervisors to ensure the quality of the data. Finally, the abstracted data was checked, cleaned and compiled by the investigators.

\section{Study Variables}

The dependent variable was the survival status of the stroke patient and the independent variables were classified as socio-demographic variables (age, sex, residency, religion, ethnicity), Stroke related clinical factors (sodium $(\mathrm{Na})$, potassium $(\mathrm{K})$, Creatinine $(\mathrm{Cr})$ level, random blood glucose level (RBS), white blood cells (WBC), red blood cells $(\mathrm{RBC})$ and platelets $(\mathrm{PL})$, types of stroke:-Ischemic stroke, hemorrhagic stroke, GCS level, previous stroke, family history, length of hospital status, clinical presentation, pulse rate, blood pressure, respiratory rate, body temperature, oxygen saturation), stroke managementrelated factors (time to have CT-scan, nursing care provide, mode of referral, time interval from symptom onset 
to hospital, history of previous medication and type of medication received at hospital), and Co-morbidities (hypertension, diabetes mellitus, heart disease, chronic kidney disease)

\section{Operational Definition}

Stroke: defined as "rapidly developing clinical signs of focal (or global) disturbance of cerebral function lasting longer than 24 hours, unless interrupted by death confirmed with CT scan/MRI. ${ }^{3}$

Event: A stroke patient who died during treatment from any cause.

Survival status: The status of the patients' survival to the outcome (death) or censored. Censored: time to event is not observed for reasons such as termination of study before all recruited subjects have shown the event or the subject has left the study prior to experiencing an event. ${ }^{37}$

Nursing management: is a treatment or care based on clinical judgment and knowledge, the nurse performs to improve patient survival status ${ }^{38}$ such as medication administration, positioning, nasogastric tube feeding, catheterization, input output measurement, fluid replacement, health education, blood sugar level measurement.

Beginning date: the first date confirmed diagnosis of stroke September 1, 2014.

The closing date: the date that is the last date of data abstraction March 25, 2020.

Follow-up time period: the time from the beginning of the study period to an event, end of the study, or loss of contact or withdrawal from the study.

Time to death: Time from the first confirmed diagnosis date of stroke to death.

Incomplete data: When dependent or one of independent variables is not registered (survival status, lab result).

\section{Data Managment and Analysis}

After the data were checked for completeness and consistency, it was entered into the Epi data version.3.1 software and exported to SPSS version 25.0 for further analysis. The data were cleaned, coded and edited before analysis. Data exploration was undertaken to see if there were odd codes or items that were not logical and then subsequent editing was done. The response variable was survival time, defined as "time in months that transpired from the date of initial stroke treatment to death" coded as one or, in the case of individuals who did not die (censored) coded as zero, "the time in days that transpired to complete stroke treatment, loss of follow-up, transfer out". For categorical variables, the descriptive variable analysis was performed and the results were expressed as frequency with percent, mean with standard deviation for normally distributed common variables, and median with interquartile range for skewed continuous variables. To identify the predictors associated with stroke, the Cox proportional hazards analysis model was computed. As a result, the bivariable and multivariable Cox proportional hazards analysis model is performed to identify variables having an association with the outcome variable. Variables with $\mathrm{p} 0.25$ are considered eligible for multivariable analysis in bivariable Cox proportional hazards analysis. The assumption for proportional hazard was assessed graphically by the log minus $\log$ survival curve and statistically and fulfilled the assumption among variables which were eligible for multivariable Cox proportional hazards analysis. Variables with a p-value of less than or equal to 0.05 were declared significantly associated with the dependent variable in multivariable Cox proportional hazards analysis. For the comparison of time to recovery among the different groups of patients, the Kaplan Meier curve with Log rank test was used to compare the survival curves of the two groups defined by categorical covariates. The adjusted hazards ratio (HR) with a $95 \%$ confidence interval (CI) was used to express the association between the outcome and the independent variable.

\section{Results}

\section{Patient Related Characteristics}

Of the total strokes, about 227 (61.7\%) were ischemic, and $141(38.3 \%)$ were the hemorrhagic type of stroke. More than half, $206(56 \%)$ of the stroke patients were male and $39(69.64 \%)$ of them were men. The age group 45-65 years old accounted for slightly more than half of all deaths (29 (51.78\%) (Table 1).

\section{Clinical and Laboratory Result Characteristics}

Regarding vital signs and laboratory results, three fourths of the $50(38.2 \%)$ of the total death body temperature was above 37.1 degree centigrade upon hospital arrival 24 hours. More than half $(31(54.4 \%))$ of stroke patients died with a heart rate of more than 100 beats per minute within 24 hours of hospital admission. Most patients, 293 (79.6\%) presented with their random blood sugar less than $170 \mathrm{mg} / \mathrm{dl}$ upon hospital arrival, and 19 patients (33.92\%) of the total RBS were greater than $200 \mathrm{mg} / \mathrm{dl}$. Most 
Table I Socio Demographic and Clinical Characteristics of Stroke Patients Admitted to FHCSH, North West Ethiopia, 2020 (N=368)

\begin{tabular}{|c|c|c|c|c|}
\hline \multirow{2}{*}{ Variables } & \multirow[t]{2}{*}{ Category } & \multicolumn{2}{|c|}{ Status at Last Contact } & \multirow[t]{2}{*}{ Total N \% } \\
\hline & & Censored & Death & \\
\hline \multirow[t]{2}{*}{ Sex } & Male & $167(81.1 \%)$ & $39(18.9 \%)$ & $206(56.0 \%)$ \\
\hline & Female & $145(89.5 \%)$ & $17(10.5 \%)$ & $162(44.0 \%)$ \\
\hline \multirow[t]{3}{*}{ Age } & $<45$ & $43(81.1 \%)$ & $10(18.9 \%)$ & $53(14.4 \%)$ \\
\hline & $45-65$ & $169(85.4 \%)$ & $29(14.6 \%)$ & $198(53.8 \%)$ \\
\hline & $>65$ & $100(85.5 \%)$ & $17(14.5 \%)$ & $117(31.8 \%)$ \\
\hline \multirow[t]{2}{*}{ History of previous stroke } & Yes & II (47.8\%) & $12(52.2 \%)$ & $23(6.3 \%)$ \\
\hline & No & $30 I(87.2 \%)$ & $44(12.8 \%)$ & $345(93.8 \%)$ \\
\hline \multirow[t]{2}{*}{ Type of stroke diagnosed } & Ischemic & 198(87.2\%) & $29(12.8 \%)$ & $227(61.7 \%)$ \\
\hline & Hemorrhagic & II 4(80.9\%) & $27(19.1 \%)$ & $|4|(38.3 \%)$ \\
\hline \multirow[t]{3}{*}{ GCS at admission } & $<8$ & $36(60.0 \%)$ & $24(40.0 \%)$ & $60(16.3 \%)$ \\
\hline & $8-12$ & $|2|(82.9 \%)$ & $25(17.1 \%)$ & $142(39.7 \%)$ \\
\hline & $13-15$ & $155(95.7 \%)$ & $7(4.3 \%)$ & $162(44.0 \%)$ \\
\hline \multirow[t]{2}{*}{ Right sided body weakness } & Yes & $12 \mid(78.1 \%)$ & $34(21.9 \%)$ & $155(42.1)$ \\
\hline & No & $191(89.7 \%)$ & $22(10.3 \%)$ & $213(57.9)$ \\
\hline
\end{tabular}

patients, $50(89.28 \%)$ of the total deaths, were presented with a creatinine level of greater than $1.2 \mathrm{mg} / \mathrm{dl}$. Patients presented with hypokalemia (potassium level less than 3.5 $\mathrm{mmol} / \mathrm{l} 53(94.64 \%)$ ) died out of the total (Table 2).

\section{Overall Survival Rate of Stroke Patients}

The study samples were followed for a minimum of 1 day and a maximum of 51 months with a median survival time of 0.26
(95\% CI: $0.136-0.74)$ months and the overall mean survival time was 5.92 (95\% CI: 4.68-7.10) months. The study participants were followed retrospectively by 2166 people for three months free of stroke. The overall death incidence density was 258 deaths per 106 people per month (Figure 1). The cumulative survival probability was computed at the end of the 1 st month, one year, two years, and four years at $81 \%, 80.72 \%$, $75.09 \%, 71.68 \%$, respectively. The survival probability is

Table 2 Clinical Conditions and Laboratory Result Related Characteristics of Hospitalized Stroke Patients Admitted to FHCSH North, West, Ethiopia, $2020(\mathrm{~N}=368)$

\begin{tabular}{|c|c|c|c|c|}
\hline \multirow[t]{2}{*}{ Variables } & \multirow[t]{2}{*}{ Category } & \multicolumn{2}{|c|}{ Status at Last Contact } & \multirow[t]{2}{*}{ Total N \% } \\
\hline & & Censored & Death & \\
\hline \multirow[t]{2}{*}{ Temperature } & $<37.1$ & $23 \mathrm{I}(97.5 \%)$ & $6(2.5 \%)$ & $237(64.4 \%)$ \\
\hline & $>37.1$ & $81(61.8 \%)$ & $50(38.2 \%)$ & $|3|(35.6 \%)$ \\
\hline \multirow[t]{2}{*}{ Heart rate } & $60-100$ & $286(92.0 \%)$ & $25(8.0 \%)$ & $311(84.5 \%)$ \\
\hline & $>100$ & $26(45.6 \%)$ & $31(54.4 \%)$ & $57(15.5 \%)$ \\
\hline \multirow[t]{3}{*}{ Random blood sugar } & $<170$ & $262(89.4 \%)$ & $3 I(10.6 \%)$ & $293(79.6 \%)$ \\
\hline & $170-200$ & $33(84.6 \%)$ & $6(15.4 \%)$ & $39(10.6 \%)$ \\
\hline & $>200$ & I7(47.2\%) & $19(52.8 \%)$ & $36(9.8 \%)$ \\
\hline \multirow[t]{3}{*}{ Creatinine } & $<0.6$ & $4(100.0 \%)$ & $0.0 \%$ & $4(1.1 \%)$ \\
\hline & $0.6-1.2$ & $235(97.5 \%)$ & $6(2.5 \%)$ & $24 I(65.5 \%)$ \\
\hline & $>1.2$ & $73(59.3 \%)$ & $50(40.7 \%)$ & $123(33.4 \%)$ \\
\hline \multirow[t]{3}{*}{ Potassium } & $<3.5$ & $108(67.1 \%)$ & $53(32.9 \%)$ & $161(43.8 \%)$ \\
\hline & $3.5-4.5$ & 164(98.2\%) & $3(1.8 \%)$ & $167(45.4 \%)$ \\
\hline & $>4.5$ & $40(100.0 \%)$ & $0.0 \%$ & $40(10.9 \%)$ \\
\hline
\end{tabular}




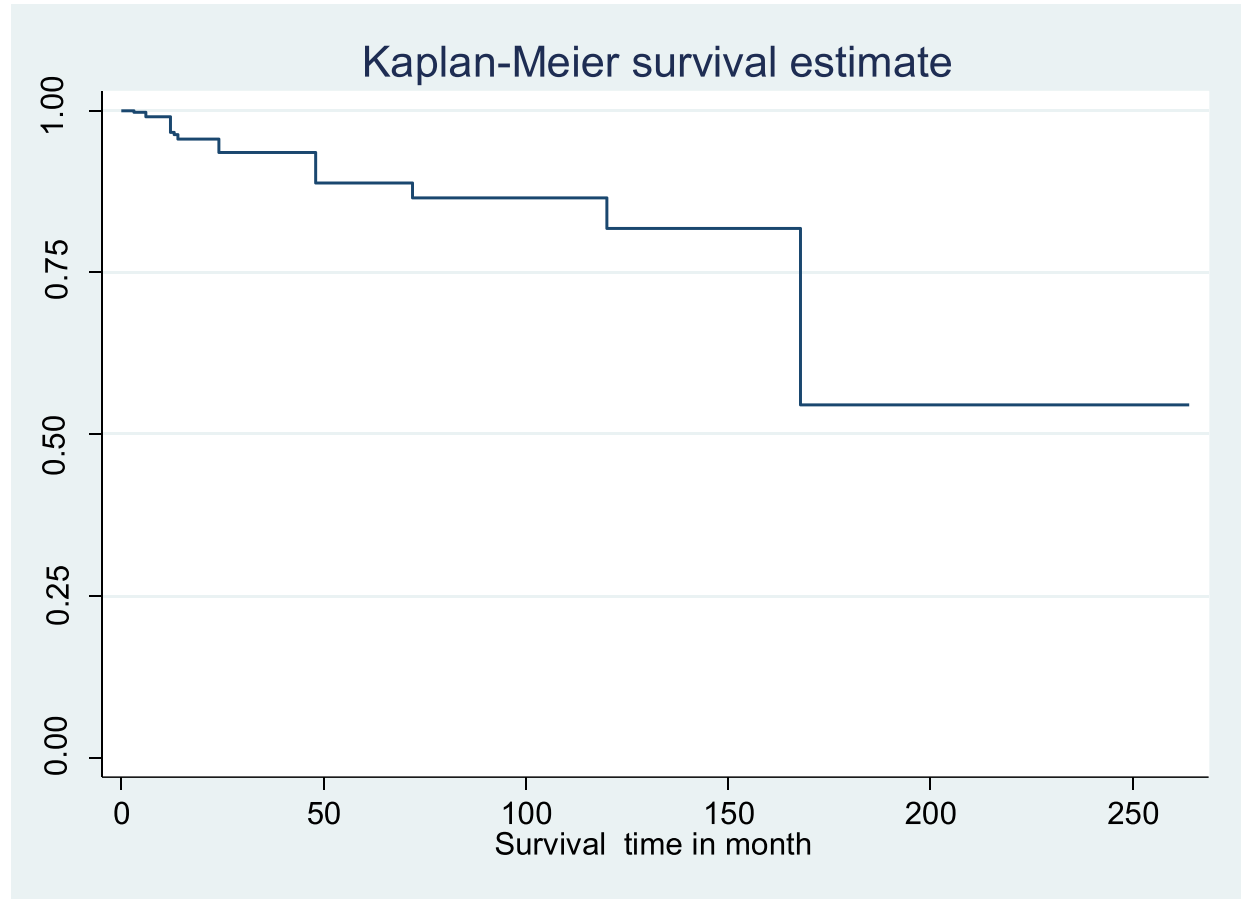

Figure I Overall Kaplan-Meier estimation of survival functions of stroke patients with $95 \% \mathrm{Cl}$ diagnosed in FHCSH North, west, Ethiopia. The subjects were monitored between Septemberl, 2014 and August 31, 2019.

highest in the first month of follow-up after a stroke is diagnosed, and then it relatively decreases as the follow-up time increases. During the follow-up period, most deaths, 51 (91.07\%), occurred within the $1^{\text {st }}$ month after the occurrence of the stroke. The average length of the hospital stay was 8.36 (95\% CI: 6.41-10.3) days.

\section{Outcomes of Stroke Patients}

During the follow-up period of the study $56(15.2 \%)$ of stroke patients were died, and $312(84.8 \%)$ were right censored (Figure 2).

\section{Predictors of Stroke}

In the bi-variable Cox proportional hazards regression analysis, ten variables (male sex, age greater than 65 years, patient with a previous stroke, presentation with right-side body weakness, left-side body weakness, GCS less than 8 , temperature above $37.1^{\circ} \mathrm{C}$, heart rate greater than 100 beats/minute, creatinine level above $1.2 \mathrm{mg} / \mathrm{dl}$, potassium less than $3.5 \mathrm{mmol} / \mathrm{l}, \mathrm{RBS}>200 \mathrm{mg} / \mathrm{dl}$ ) were the predictive predictors of mortality.

In the multivariable Cox regression analysis, only four variables were identified as the predictors of mortality. These were, age greater than 65 years $(\mathrm{AHR}=14.2)$, temperature above $37.1^{\circ} \mathrm{C}(\mathrm{AHR}=7.14), \mathrm{K}$ less than $3.5 \mathrm{mmol}$
(AHR=6.82), Creatinine greater than $1.2 \mathrm{mg} / \mathrm{dl}$ $(\mathrm{AHR}=7.85)$.

Specifically, the risk of mortality among stroke patients with an age greater than 65 years admitted to hospital was

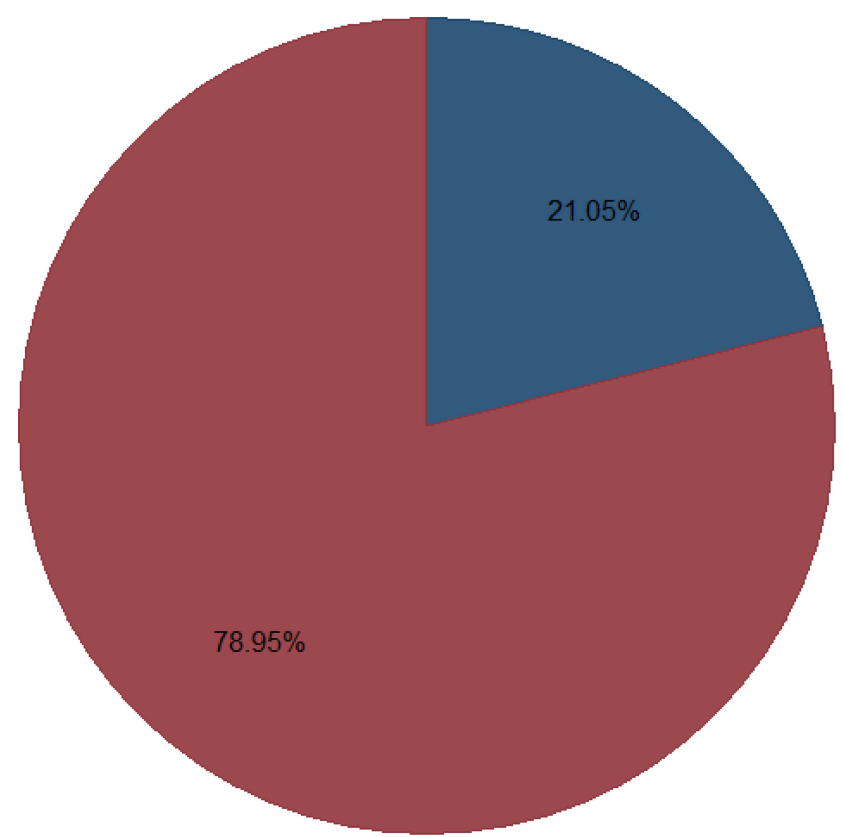

Figure 2 Status of stroke patient during four-year follow-up in $\mathrm{FHCSH}$, medical department from September I, 2014 to August 3I, 2019. Blue= died, red= censored. 
14.2 times higher as compared to an age of less than 45 $(\mathrm{AHR}=14.2,95 \%$ CI 3.2-62, $\mathrm{p}=0.0001)$. Patients presented with their body temperature 37.1 and over during 24 hours of hospital admission was 7.14 times at higher risk to $\operatorname{die}(\mathrm{AHR}=7.14,95 \% \mathrm{CI}: 2.76-18.5, \mathrm{p}=0.001)$ than those body temperature below $37.1^{\circ} \mathrm{C}$ (Figure 3 ). Those stroke patients whose potassium levels below 3.5 and the creatinine levels above 1.2 were 6.82 and 7.85 times at higher risk of death than a potassium level between 3.5 and 4.5 (AHR $=6.82$, 95\% CI: 1.9-23.53, $\mathrm{p}=0.009$ ) and creatinine level between 0.6 and $1.2 \mathrm{mg} / \mathrm{dl}(\mathrm{AHR}=7.85$, 95\% CI: 2.7-22.6, p=0.001) (Figure 4) (Table 3).

\section{Discussion}

The overall survival rate for one month, twelve months, four months, and eight months was $81.39 \%, 80.72 \%$, $75.09 \%$, and $71.68 \%$, respectively, with an overall survival rate of $72.2 \%$. Age greater than 65 years, body temperature above 37.1 degree centigrade, potassium less than 3.5 $\mathrm{mmol} / \mathrm{l}$, creatinine level greater than $1.2 \mathrm{mg} / \mathrm{dl}$, after admissions were the independent predictors of mortality with p-value less than 0.05 .

During the follow-up period, $56(15.2 \%)$ of stroke patients died, according to this study. This finding is consistent with a $15.7 \%$ survival rate in Finland, ${ }^{39}$ a $37-$ month FHCSH survival rate after 36 months of follow-up, ${ }^{39}$ thirty-seven month survival rate FHCSH after thirty-six follow-up, ${ }^{37}$ and a month-long analysis and systematic review study in the United Kingdom. ${ }^{40,41}$

But the survival rate of twelve months in this study is higher than the result reported $(79.2 \%)$ in Lithuania, ${ }^{42}$ $59.3 \%$ in Kenya. $^{43}$ The disparity may be explained by the sample size difference, with inclusion criteria for an age range of 25-64 years in Lithuania and 719 study participants across three hospitals in Kenya, whereas our study is a single hospital-based study. On the same way, the current finding is higher than compared with survival of $39.7 \%$ in Tanzania, ${ }^{44}$ with a one-month follow-up duration. This disparity could be attributed to differences in study setup.

Similarly, this study's two-year survival rate of $75.09 \%$ is higher than the findings of the Iranian study, with stroke survival accounting for $62 \%$ of the two years. ${ }^{45}$ This disparity could be attributed to sample size and study design. On the same way, the current one-year survival rate $80.72 \%$ finding is found to be higher than compared with $39 \%$ of survival at one year in Rwanda, probably this variation could be resulted from small sample size in Rwanda 96 stroke patient and it was a prospective study which helps to follow patients and can detect true survival rate but in our study there was large proportion of censored $84.4 \%$ which makes increase survival rate. Likewise,

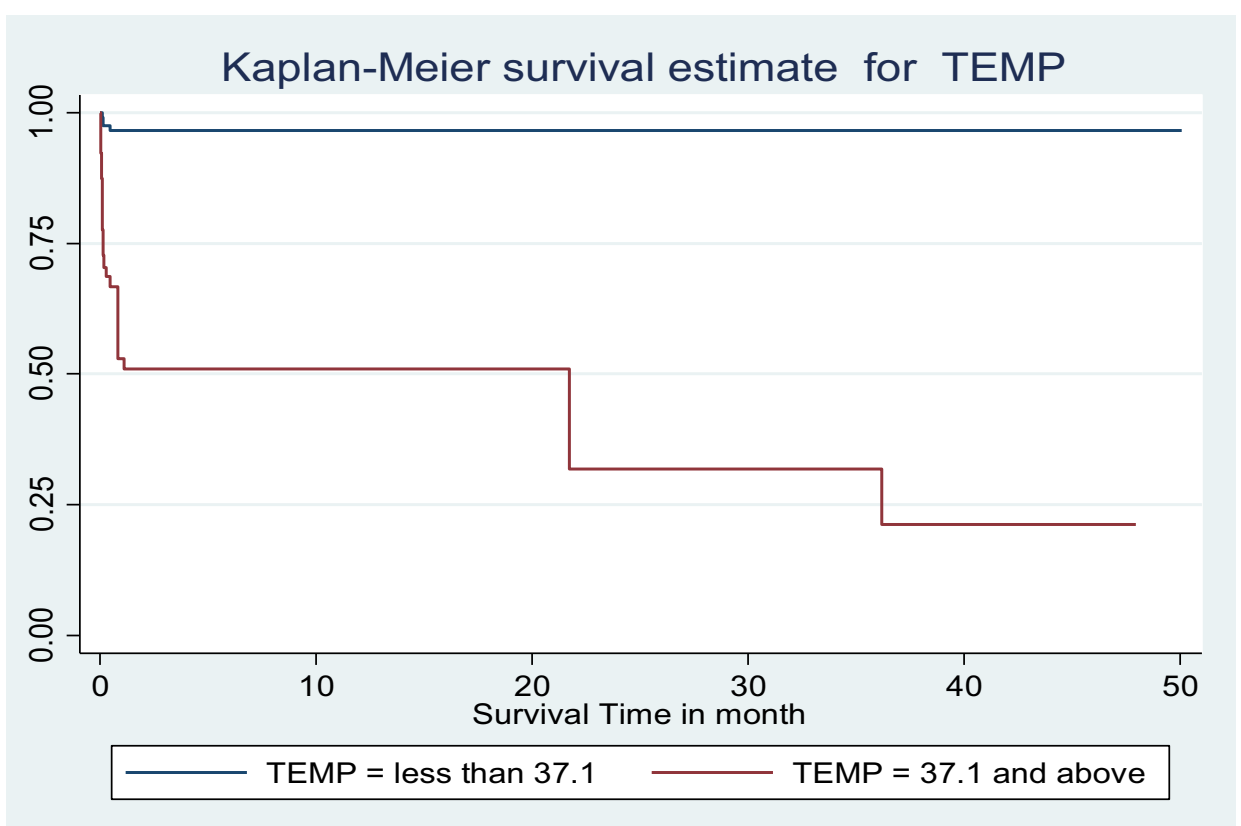

Figure 3 Kaplan-Meier survival plot of predictors derived from log rank by temperature in $(p=0.00 \mathrm{I})$ associated with survival status of patient with stroke admitted to FHCSH, Northwest Ethiopia. 


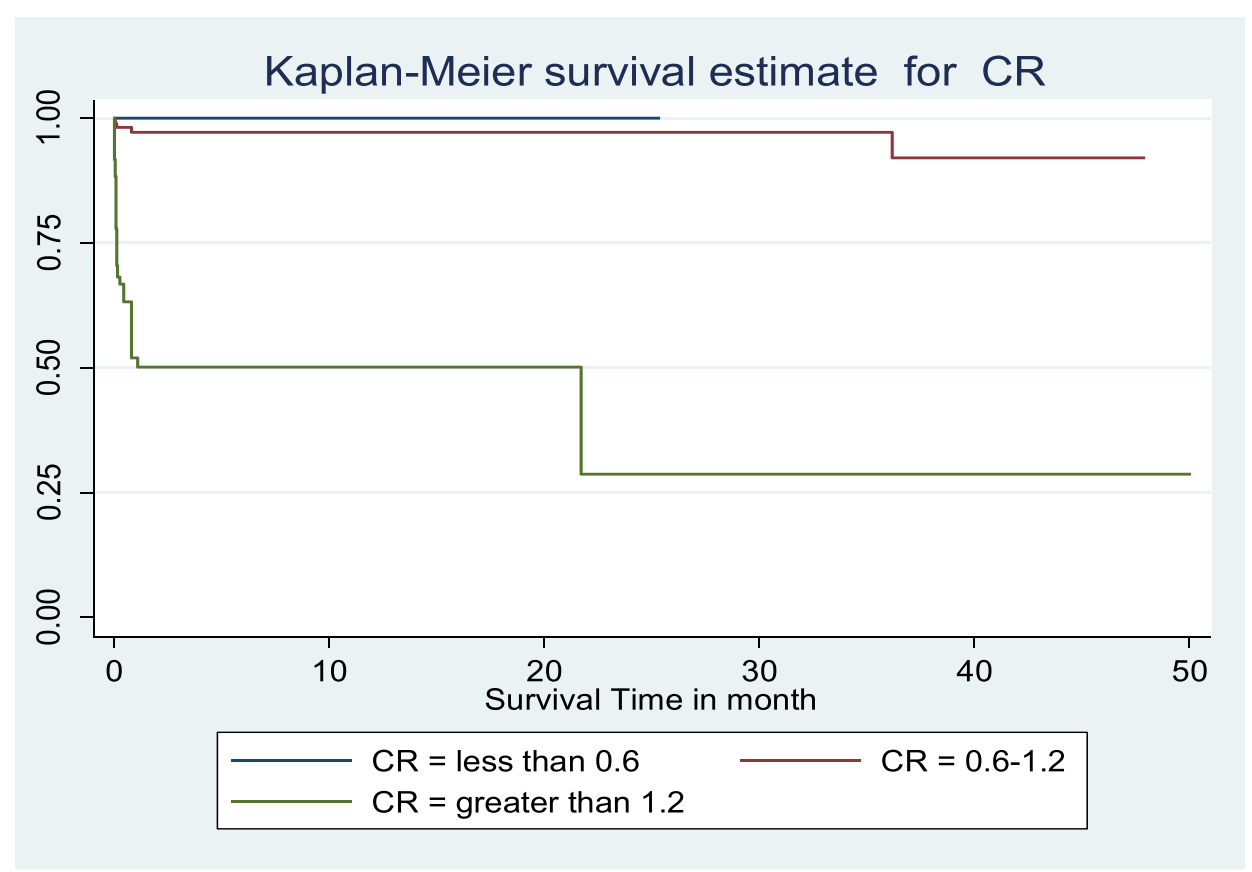

Figure 4 Kaplan-Meier survival plot of predictors derived from log rank by creatinine level in $D(p=0.00 \mathrm{I})$ associated with survival status of patient with stroke admitted to FHCSH, Northwest Ethiopia.

the 30 -day survival rate $81.39 \%$ of this study is higher than $69.8 \%$ survival rate of Jimma at one month. ${ }^{46}$ The difference might be due to the study design at Jimma. It was a prospective study and assessed by close follow-up of the patient through telephone interview of the patient/ caregiver after patients were discharged from the hospital, which can determine the true survival rate.

In contradiction to the above the survival rate in this study is lower as compared to studies conducted in Australia $85.1 \%$ were survived at one year. ${ }^{20}$ The large sample size of 81,703 study participants in our study, eight years registered stroke data, could be due to differences in patients' characteristics or health-care system, and there could be a difference in early implementation, advanced treatment modality and adherence to treatment, early screening and detection. That could be because, in Australia, patients may be seen by a neurologist to treat stroke patients, and studies show that patients who are seen by a neurologist have a better outcome. ${ }^{36,47,48}$

In the same way, the one-year survival rate of the current finding, $81.39 \%$, is found to be lower compared with $91.8 \%$ of the one-year survival rate in China. ${ }^{49}$ The difference could be due to inclusion criteria (our study focused on both types of stroke, whereas the previous study only on ischemic stroke), management team and supplies, patient load, patient clinical profile, and a difference in following management protocol. Before 2018, the hospital had no CT-Scan machine. For this, a patient went to a private hospital to have a CT-Scan and it takes a long time to receive stroke medicine, which greater than one hour to less than one hour of AHA/ASA recommendation which has an effect on stroke even if it is not significant for mortality in our study. ${ }^{36}$

The average length of stay in hospital in this study was 8.36 days, which is consistent with the results reported from the study in Nekemte, Ethiopia, and Jimma in which the average length of stay was 7 and 9.2 days, respectively. ${ }^{14,31}$ However, this is lower than in the study in Addis Ababa, which was 12.59 days. ${ }^{50}$ In contradiction to the above, this result was found to be longer as compared to other reported studies from Ambo University hospital (5 days). ${ }^{51}$ The difference can be explained by differences in stroke patients' clinical profiles when they develop chronic comorbidities such as hypertension and complications, which may cause them to spend more time in hospitals. ${ }^{33}$

In this study, stroke patients over the age of 65 had 6.3 times the risk of dying (AHR $=6.3,95 \%$ CI: 1.74-22.74) as those under the age of 45 . This is similar to two studies conducted in Iran, ${ }^{18,45}$ in United States, ${ }^{52,53} \mathrm{UK},{ }^{40}$ Kenya, ${ }^{43}$ older age was the predictors of mortality. The survival difference between young and older stroke 
Table 3 Bi-Variable and Multivariable Analysis Predictors of Mortality Among Stroke Patients Admitted to FHCSH, North West Ethiopia, $2020(\mathrm{~N}=368)$

\begin{tabular}{|c|c|c|c|c|c|c|c|}
\hline \multirow[t]{2}{*}{ Variables } & \multirow[t]{2}{*}{ Category } & \multicolumn{2}{|c|}{ Survival Status } & \multirow[t]{2}{*}{$\mathrm{CHR}(95 \% \mathrm{Cl})$} & \multirow[t]{2}{*}{$P$ value } & \multirow[t]{2}{*}{ AHR $(95 \% \mathrm{Cl})$} & \multirow[t]{2}{*}{$P$ value } \\
\hline & & Death N (\%) & Censored N (\%) & & & & \\
\hline Sex & $\begin{array}{l}\text { Male } \\
\text { Female }\end{array}$ & $\begin{array}{l}167(81.1) \\
145(89.5)\end{array}$ & $\begin{array}{l}39(18.9) \\
17(10.5)\end{array}$ & $\begin{array}{l}2.24(1.23-4.1) \\
1\end{array}$ & 0.008 & $\begin{array}{l}\text { I.23(0.59-2.54) } \\
\text { । }\end{array}$ & 0.88 \\
\hline Age & $\begin{array}{l}<45 \\
45-65 \\
>65\end{array}$ & $\begin{array}{l}43(81.1) \\
169(85.4) \\
100(85.5)\end{array}$ & $\begin{array}{l}10(18.9) \\
29(14.6) \\
17(14.5)\end{array}$ & $\begin{array}{l}\text { I } \\
\text { I. } 20(0.5 I-2.9) \\
\text { I.85 (0.7I-4.8) }\end{array}$ & $\begin{array}{l}0.6 \\
0.2\end{array}$ & $\begin{array}{l}\text { I } \\
3.14(1.1-9.03) \\
14.2(3.2-62.1)\end{array}$ & $\begin{array}{l}0.5 \\
0.00\end{array}$ \\
\hline PRSTR & $\begin{array}{l}\text { Yes } \\
\text { No }\end{array}$ & $\begin{array}{l}\mathrm{II}(47.8) \\
30 \mathrm{I}(87.2)\end{array}$ & $\begin{array}{l}12(52.2) \\
44(12.8)\end{array}$ & $\begin{array}{l}4.15(2.2-7.9) \\
1\end{array}$ & 0.000 & $\begin{array}{l}\text { I.I }(0.48-2.5 \mathrm{I}) \\
\mathrm{I}\end{array}$ & 0.53 \\
\hline RSBW & $\begin{array}{l}\text { Yes } \\
\text { No }\end{array}$ & $\begin{array}{l}121(78.1) \\
191(89.7)\end{array}$ & $\begin{array}{l}34(21.9) \\
22(10.3)\end{array}$ & $\begin{array}{l}2.43(1.4-4.2) \\
\mathrm{I}\end{array}$ & 0.002 & $\begin{array}{l}4.11(1.73-9.79) \\
\text { I }\end{array}$ & 0.92 \\
\hline Left side body weakness & $\begin{array}{l}\text { Yes } \\
\text { No }\end{array}$ & $\begin{array}{l}125(91.9) \\
187(80.6)\end{array}$ & $\begin{array}{l}I I(8.1) \\
45(19.4)\end{array}$ & $\begin{array}{l}0.4 I(0.2-0.8) \\
I\end{array}$ & 0.009 & $\begin{array}{l}2.44(0.86-8.69) \\
\text { I }\end{array}$ & 0.09 \\
\hline GCS & $\begin{array}{l}<8 \\
8-12 \\
13-15\end{array}$ & $\begin{array}{l}36(60.0) \\
121(82.9) \\
155(95.7)\end{array}$ & $\begin{array}{l}24(40.0) \\
25(17.1) \\
7(4.3)\end{array}$ & $\begin{array}{l}4.18(2.25-7.4) \\
0.24(0.1-0.6) \\
\text { I }\end{array}$ & $\begin{array}{l}0.043 \\
0.06\end{array}$ & $\begin{array}{l}2.7(1.2-6.12) \\
1.24(0.4-3.82) \\
\text { I }\end{array}$ & $\begin{array}{l}0.07 \\
0.08\end{array}$ \\
\hline TEMP & $\begin{array}{l}<37.1 \\
>37.1\end{array}$ & $\begin{array}{l}231(97.5) \\
8 I(6 I .8)\end{array}$ & $\begin{array}{l}6(2.5) \\
50(38.2)\end{array}$ & $\begin{array}{l}1 \\
13(5.3-17)\end{array}$ & 0.0001 & $\begin{array}{l}\text { I } \\
7.14(2.76-18.5)\end{array}$ & 0.01 \\
\hline Potassium & $\begin{array}{l}<3.5 \\
3.5-4.5\end{array}$ & $\begin{array}{l}108(67.1) \\
164(98.2)\end{array}$ & $\begin{array}{l}53(32.9) \\
3(1.8)\end{array}$ & $\begin{array}{l}21.7(6.8,69.7) \\
1\end{array}$ & 0.0001 & $\begin{array}{l}6.82(1.9-23.53) \\
1\end{array}$ & 0.009 \\
\hline Creatinine & $\begin{array}{l}0.6-1.2 \\
>1.2\end{array}$ & $\begin{array}{l}235(97.5) \\
73(59.3)\end{array}$ & $\begin{array}{l}6(2.5) \\
50(40.7)\end{array}$ & $\begin{array}{l}\text { I } \\
21.2(8.5-52.9)\end{array}$ & 0.0001 & $\begin{array}{l}\text { I } \\
7.85(2.7-22.6)\end{array}$ & 0.001 \\
\hline Random blood sugar & $\begin{array}{l}<170 \\
170-200 \\
>200\end{array}$ & $\begin{array}{l}262(89.4) \\
33(84.6) \\
17(47.2)\end{array}$ & $\begin{array}{l}31(10.6) \\
6(15.4) \\
19(52.8)\end{array}$ & $\begin{array}{l}\text { I.I8(0.47-2.9) } \\
\text { I } \\
6.14(2.1-17.9)\end{array}$ & $\begin{array}{l}0.729 \\
0.001\end{array}$ & $\begin{array}{l}1.13(0.4-3.18) \\
\text { I } \\
7.33(1.8-29.9)\end{array}$ & $\begin{array}{l}0.06 \\
0.09\end{array}$ \\
\hline
\end{tabular}

patients arises from different attributes of survival such as difference in treatment modalities, the unfavorable effects of medication and intoxication, comorbidity in older patients, and low progression of disease in older patients. Whereas study in Ethiopia ${ }^{50,54}$ shows age has no association with mortality.

Patients who had a body temperature greater than 37.1 degree centigrade after admission were 7.14 times (AHR $=7.14,95 \%$ CI: 2.76-18.49) at risk of earlier death as compared with patients whose body temperature was less than 37.1 degree centigrade. Similar findings have been reported in previous Tanzanian studies. ${ }^{44}$ This could be due to the fact that fever has a direct impact on the neurological outcome following a stroke. On a local level, fever results in elevated levels of excitatory amino acids (glutamate and dopamine), free radicals, lactic acid, and pyruvate, increased ischemic depolarizations, blood-brain barrier breakdown, and impaired enzymatic function and reduced cytoskeletal stability. Globally, these events lead to cerebral edema, potentially reducing cerebral perfusion pressure, and larger volumes of ischemic injury. ${ }^{26,28}$

In the current study, 50 (13.58\%) of stroke patients had their creatinine level $>1.2 \mathrm{mg} / \mathrm{dl}$. For this reason, a significantly increased risk of death was found with a creatinine of greater than $1.2 \mathrm{mg} / \mathrm{dl}(\mathrm{AHR}=7.85,95 \%$ CI: 2.72-22.65). This finding is consistent with another Gondar study $(\mathrm{AHR}=8.848,95 \%$ CI: $1.616-67.437) .{ }^{33}$ Potassium level less than $3.5 \mathrm{mmol} / \mathrm{l}$ was also found to be associated with increased (AHR $=6.82,95 \%$ CI: $1.97-$ 23.5 at $\mathrm{P}<0.05$ ) risk of death as seen in the study done in Nilratan Sircar Medical College \& Hospital, Kolkata, with hypokalemia (Potassium level less than $3.5 \mathrm{mmol} / \mathrm{l}$ ) with stroke, died $(p=0.0043) .{ }^{34}$ Therefore, the beneficial effect of screening and treatment of fever, creatinine greater than 
$1.2 \mathrm{mg} / \mathrm{dl}$ and potassium less than $3.5 \mathrm{mmol} / 1$ on the survival of stroke patients can not be overemphasized. The findings of this research may provide necessary information on areas of improvement. However, further research is needed to give policy-level recommendations.

\section{Limitations of the Study}

This is a (referral) hospital-based study, and we may not have recruited a representative sample of stroke patients in FHCSH, as less severe cases of stroke may not have been admitted or referred for further management (referral bias). Thus, milder forms of stroke and stroke deaths in the community could have gone unnoticed if they had not been admitted to the hospital. Due to retrospective nature of the study, some important predictors which might have significant prediction for stroke mortality (treatment adherence, physical exercise, educational status and multidisciplinary care) could not be found on the medical cards and were not assessed. Our study also excludes stroke patients who received treatment at private health institutions, as well as patients who received treatment at an emergency department and either went home for a full recovery or died there. A study from Mexico concluded that private hospital deaths account for up to $10 \%$ of stroke deaths, ${ }^{47}$ due to this reason accurate survival rate of stroke patients in our study may be biased.

\section{Recommendations}

As a result of this study, early diagnosis and management of cases in hospital according to the national protocol is in need with special emphasis on stroke patients with interventions (monitor vital signs frequently, do renal function tests and serum electrolytes and manage accordingly) should focus on patients having an age greater than 65 years, body temperature above $37.1^{\circ} \mathrm{C}$, potassium less than $3.5 \mathrm{mmol} / \mathrm{l}$, and creatinine level greater than $1.2 \mathrm{mg} / \mathrm{dl}$ to prevent further mortality. Finally, prospective communitybased studies should be conducted to define the incidence and the associated predictors in the general population.

\section{Conclusion}

The findings of this study revealed a lower survival probability of confirmed stroke patients in FHCSH as compared with those of high- and middle-income countries. Age greater than 65 years, body temperature above 37.1degrees centigrade, potassium less than $3.5 \mathrm{mmol} / \mathrm{l}$, Creatinine greater than $1.2 \mathrm{mg} / \mathrm{dl}$, after admission are the independent predictors of mortality.

\section{Abbreviations}

AOR, adjusted odds ratio; AHR, adjusted hazard ratio; CT, computed tomography; DALY, disability adjusted life years; FHCSH, Felege Hiwot comprehensive specialized Hospital; GBD, global burden of disease; GCS, Glasgow Coma Scale; IHRERC, Institutional Health Research Ethical Review Committee; MRI, magnetic resonance imaging; LMICs, low- to middle-income countries; NCD, non communicable disease; RBS, random blood sugar level; SPSS, statically package social science; WHO, World Health Organization.

\section{Data Sharing Statement}

The materials and data of this study are available from Molla Yigzaw Birhanu, the corresponding author upon request.

\section{Ethical Consideration}

We obtained the ethical clearance approval letter from the Bahirdar University College of medicine and health sciences Institutional Health Research Ethical Review Committee (IHRERC), with the protocol number 0050/ 2020. During data collection period, the written informed consent was taken from all study participants' (stroke patients). During the data collection period, the administrative bodies of Felege Hiwot Comprehensive Specialized Hospital were also allowed to conduct the research by providing permissionT. To keep the confidentiality, the information of the study participants was not disclosed to anyone other than the principal investigators. Generally, this study was conducted in accordance with the World Medical Association Declaration of Helsinki.

\section{Acknowledgments}

The authors extended their special thanks for both data collectors and supervisor.

\section{Funding}

No financial support was gained to conduct the study.

\section{Disclosure}

The authors state that they have no conflicts of interest for this work.

\section{References}

1. Hatano S. Experience from a multicentre stroke register: a preliminary report. Bull World Health Organ. 1976;54(5):541.

2. Aseffa S, Stutzman S, Kamal A, et al. The Case for an Amharic Term for Stroke: "Ye-Angol Tikat". J Neurosci Nursing. 2019;51(2):69-73. doi:10.1097/JNN.0000000000000422 
3. Sacco R, Rabinstein AA, Carhuapoma JR, et al. American Heart Association Stroke Council, Council on Cardiovascular Surgery and Anesthesia; Council on Cardiovascular Radiology and Intervention; Council on Cardiovascular and Stroke Nursing; Council on Epidemiology and Prevention; Council on Peripheral Vascular Disease; Council on Nutrition, Physical Activity and Metabolism. An updated definition of stroke for the 21st century: a statement for healthcare professionals from the American Heart Association/ American Stroke Association. Stroke. 2013;44(7):2064-2089. doi:10.1161/STR.0b013e318296aeca

4. Deresse B, Shaweno D. Epidemiology and in-hospital outcome of stroke in South Ethiopia. J Neurol Sci. 2015;355(1-2):138-142. doi:10.1016/j.jns.2015.06.001

5. Mulatu G. Types and Associated Factor of Stroke at Selected Public Referral Hospitals in Addis Ababa; Ethiopia. Addis Ababa University; 2017.

6. Erkabu SG, Agedie Y, Mihretu DD, et al. Ischemic and Hemorrhagic Stroke in Bahir Dar, Ethiopia: a Retrospective Hospital-Based Study. J Stroke Cerebrovascular Dis. 2018;27(6):1533-1538. doi:10.1016/j. jstrokecerebrovasdis.2017.12.050

7. Gedefa B, et al. Assessment of risk factors and treatment outcome of stroke admissions at St. Paul's teaching hospital, addis ababa, Ethiopia. J Neurol Neurophysiol. 2017;8(3):1-6.

8. Beza M, et al. Magnitude of stroke and associated factors among patients who attended the medical ward of Felege Hiwot Referral Hospital, Bahir Dar town, northwest Ethiopia. Ethiopian J Health Dev. 2016;30(3):129-134.

9. Namale G, Kamacooko O, Kinengyere A, et al. Risk factors for hemorrhagic and ischemic stroke in Sub-Saharan Africa. J Trop Med. 2018;2018:2018. doi:10.1155/2018/4650851

10. Akinyemi RO, Owolabi MO, Ihara M, et al. Stroke, cerebrovascular diseases and vascular cognitive impairment in Africa. Brain Res Bull. 2019;145:97-108. doi:10.1016/j.brainresbull.2018.05.018

11. Matuja S, Munseri P, Khanbhai K. The burden and outcomes of stroke in young adults at a tertiary hospital in Tanzania: a comparison with older adults. BMC Med. 2020.

12. Song S, Hua C, Dornbors D, et al. Baseline red blood cell distribution width as a predictor of stroke occurrence and outcome: a comprehensive Meta-Analysis of 31 studies. Front Neurol. 2019;10:1237. doi:10.3389/fneur.2019.01237

13. Kassaw A. Prevalence, Nursing Managements and Patients" Outcomes Among Stroke Patients Admitted to Tikur Anbessa Specialized Hospital, Addis Ababa, Ethiopia, 2018. Addis Ababa Universty; 2018.

14. Fekadu G, Adola B, Mosisa G, et al. Clinical characteristics and treatment outcomes among stroke patients hospitalized to Nekemte referral hospital, western Ethiopia. Jo Clin Neurosci. 2020;71:170-176. doi:10.1016/j.jocn.2019.08.075

15. Avan A, Digaleh H, Di Napoli M, et al. Socioeconomic status and stroke incidence, prevalence, mortality, and worldwide burden: an ecological analysis from the Global Burden of Disease Study 2017. BMC Med. 2019;17(1):191. doi:10.1186/s12916-019-1397-3

16. Feigin V, Vos T. The Global Burden of Disease Brain Summit. Neuroepidemiology. 2019;52:3-16.

17. Johnson CO, Nguyen M, Roth GA, et al. Global, regional, and national burden of stroke, 1990-2016: a systematic analysis for the Global Burden of Disease Study 2016. Lancet Neurol. 2019;18 (5):439-458. doi:10.1016/S1474-4422(19)30034-1

18. Farzadfard MT, Thrift AG, Amiri A, et al. Five-year case fatality following first-ever stroke in the Mashhad stroke incidence study: a population-based study of stroke in the Middle East. J Stroke Cerebrovascular Dis. 2018;27(4):1085-1089. doi:10.1016/j. jstrokecerebrovasdis.2017.11.018

19. Thomas J, Saw KL, Adie K. Stroke mortality audit using the Structured Judgement Review method. Clin Med (Northfield Il). 2019;19(2):185. doi:10.7861/clinmedicine.19-2-185
20. Gattellari M, et al. Population-based stroke surveillance using Big Data: epidemiological trends in admissions and mortality in Australia. medRxiv. 2020.

21. Mersha AG, Abegaz TM, Seid MA, et al. Mortality rate and predictors of Stroke: a Meta-Analysis and Systematic Review. 2019

22. Nkusi AE, Muneza S, Nshuti S, et al. Stroke burden in Rwanda: a multicenter study of stroke management and outcome. World Neurosurg. 2017;106:462-469. doi:10.1016/j.wneu.2017.06.163

23. Feigin VL, Mensah GA, Norrving B, et al. Atlas of the global burden of stroke (1990-2013): the GBD 2013 study. Neuroepidemiology. 2015;45(3):230-236. doi:10.1159/000441106

24. Owolabi M, Olowoyo P, Popoola F, et al. The epidemiology of stroke in Africa: a systematic review of existing methods and new approaches. J Clin Hypertension. 2018;20(1):47-55. doi:10.1111/ jch. 13152

25. Olibamoyo O, Adewuya A, Ola B, et al. Prevalence and correlates of depression among Nigerian stroke survivors. South African $J$ Psychiatry. 2019;25(1):1-7. doi:10.4102/sajpsychiatry.v25i0.1252

26. Muscari A, Faccioli L, Lega MV, et al. Predicting cerebral edema in ischemic stroke patients. Neurological Sci. 2019;40(4):745-752. doi:10.1007/s10072-019-3717-y

27. Fekadu G, Adola B, Mosisa G, et al. Clinical characteristics and treatment outcomes among stroke patients hospitalized to Nekemte referral hospital, western Ethiopia. Jo Clin Neurosci. 2019;71.

28. Gebremariam SA, Yang HS. Types, risk profiles, and outcomes of stroke patients in a tertiary teaching hospital in northern Ethiopia. eNeurologicalSci. 2016;3:41-47. doi:10.1016/j.ensci.2016.02.010

29. Shiferaw F, et al. Non-communicable Diseases in Ethiopia: disease burden, gaps in health care delivery and strategic directions. Ethiopian J Health Dev. 2018;32:455.

30. Nuru N, Zewdu F, Amsalu S, et al. Knowledge and practice of nurses towards prevention of pressure ulcer and associated factors in Gondar University Hospital, Northwest Ethiopia. BMC Nurs. 2015;14(1):34. doi:10.1186/s12912-015-0076-8

31. Fekadu G, Chelkeba L, Kebede A. Burden, clinical outcomes and predictors of time to in hospital mortality among adult patients admitted to stroke unit of Jimma University Medical Center: a prospective cohort study. BMC Neurol. 2019;19(1):213. doi:10.1186/s12883-019-1439-7

32. Farooq MU, Chaudhry AH, Amin K, et al. The WHO STEPwise Approach to Stroke Surveillance. J Coll Phys Surgeons. 2008;18 (10):665. doi:10.2008/JCPSP.665665

33. Gebreyohannes EA, Bhagavathula AS, Abebe TB, et al. In-Hospital Mortality among Ischemic Stroke Patients in Gondar University Hospital: a Retrospective Cohort Study. Stroke Res Treat. 2019;2019:1-7. doi:10.1155/2019/7275063

34. Bandopadhyay M, et al. Study of electrolyte abnormality in acute stroke. Ann Intl Med Dental Res. 2017;3:4-9.

35. Chen Z, Jia Q, Liu C. Association of Hyponatremia and Risk of Short-and Long-Term Mortality in Patients with Stroke: a Systematic Review and Meta-Analysis. J Stroke Cerebrovascular Dis. 2019;28 (6):1674-1683. doi:10.1016/j.jstrokecerebrovasdis.2019.02.021

36. Powers WJ, Rabinstein AA, Ackerson T, et al. 2018 guidelines for the early management of patients with acute ischemic stroke: a guideline for healthcare professionals from the American Heart Association/American Stroke Association. stroke. 2018;49(3):e46e99. doi:10.1161/STR.0000000000000158

37. Kassie A, Ayalew S, Abere M. Survival Time of Adult Ischemic Stroke Patients and Associated Risk Factors: a Retrospective Cohort Study at FelegeHiwot Referral Hospital. Ann Intl Med Dental Res. 2020.

38. Davis C, Lockhart L. Update: stroke guidelines. Nurs Manage. 2016;47(2):24-33. doi:10.1097/01.NUMA.0000479442.68020.46

39. Aarnio K, Haapaniemi E, Melkas S, et al. Long-term mortality after first-ever and recurrent stroke in young adults. Stroke. 2014;45 (9):2670-2676. doi:10.1161/STROKEAHA.114.005648 
40. Tinker RJ, et al. Predictors of mortality and disability in stroke-associated pneumonia. Acta Neurol Belg. 2019;1-7.

41. Mersha AG, Abegaz TM, Seid MA, et al. Mortality rate and predictors of Stroke: a Meta-Analysis and Systematic Review. 2019.

42. Radisauskas R, Tamosiunas A, Kranciukaite-Butylkiniene D, et al. Long-term survival after stroke in Lithuania: data from Kaunas population-based stroke registry. PLoS One. 2019;14(7):e0219392. doi:10.1371/journal.pone.0219392

43. Kaduka L, Muniu E, Oduor C, et al. Stroke mortality in Kenya's public tertiary hospitals: a prospective facility-based study. Cerebrovasc Dis Extra. 2018;8(2):70-79. doi:10.1159/000488205

44. Matuja SS, Munseri P, Khanbhai K. The burden and outcomes of stroke in young adults at a tertiary hospital in Tanzania: a comparison with older adults. BMC Neurol. 2020;20(1):1-10. doi:10.1186/ s12883-020-01793-2

45. Novbakht H, Shamshirgaran SM, Sarbakhsh P, et al. Predictors of long-term mortality after first-ever stroke. J Educ Health Promot. 2020;9:9. doi:10.4103/jehp.jehp_8_19

46. Fekadu G, Chelkeba L, Melaku T, et al. 30-day and 60-day rates and predictors of mortality among adult stroke patients: prospective cohort study. Ann Med Surgery. 2020;53:1-11. doi:10.1016/j. amsu.2020.03.001

47. Ruiz-Sandoval JL, Briseño-Godínez ME, Chiquete-Anaya E, et al. Public and Private Hospital Care Disparities of Ischemic Stroke in Mexico: results from the Primer Registro Mexicano de Isquemia Cerebral (PREMIER) Study. J Stroke Cerebrovascular Dis. 2018;27 (2):445-453. doi:10.1016/j.jstrokecerebrovasdis.2017.09.025
48. Smith MA, Liou J-I, Frytak JR, et al. 30-day survival and rehospitalization for stroke patients according to physician specialty. Cerebrovascular Dis. 2006;22(1):21-26. doi:10.1159/000092333

49. Yang M, Pan Y, Li Z, et al. Platelet count predicts adverse clinical outcomes after ischemic stroke or TIA: subgroup analysis of CNSR II. Front Neurol. 2019;10:370. doi:10.3389/fneur.2019.00370

50. Mamushet Y, Zenebe G, Addissie A. Medical and neurological complications among stroke patients admitted for inpatient care in Addis Ababa, Ethiopia. Ethiop Med J. 2015;53(1):9-17.

51. Guye Betero GT, Degu A, Kefele B. Management practice, and treatment outcome and its associated factors among hospitalized stroke patient at Ambo University Referral Hospital, Ethiopia: an Institutional Based Cross Sectional Study. 2019

52. Elfassy T, Grasset L, Glymour MM, et al. Sociodemographic Disparities in Long-Term Mortality Among Stroke Survivors in the United States: the REGARDS Study. Stroke. 2019;50(4):805-812. doi:10.1161/STROKEAHA.118.023782

53. de Oliveira ADP, de Andrade-valença LPA, Valença MM. Factors Associated With In-Hospital Mortality in Very Elderly Patients With Ischemic Stroke: a Cohort Study. J Stroke Cerebrovascular Dis. 2019;28(10):104281. doi:10.1016/j.jstrokecerebrovasdis.2019.06.039

54. Temesgen TG, Teshome B, Njogu P. Treatment outcomes and associated factors among hospitalized stroke patients at Shashemene Referral Hospital, Ethiopia. Stroke Res Treat. 2018;2018:1-5. doi:10.1155/2018/8079578
Risk Management and Healthcare Policy

\section{Publish your work in this journal}

Risk Management and Healthcare Policy is an international, peerreviewed, open access journal focusing on all aspects of public health, policy, and preventative measures to promote good health and improve morbidity and mortality in the population. The journal welcomes submitted papers covering original research, basic science, clinical \& epidemiological studies, reviews and evaluations,
Dovepress

guidelines, expert opinion and commentary, case reports and extended reports. The manuscript management system is completely online and includes a very quick and fair peer-review system, which is all easy to use. Visit http://www.dovepress.com/testimonials.php to read real quotes from published authors. 